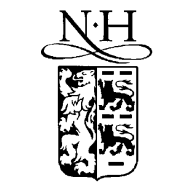

ELSEVIER

\title{
Paper: a study on the certification of the information security management systems
}

\author{
Andrew Ren-Wei Fung ${ }^{\mathrm{a}}$, Kwo-Jean Farn ${ }^{\mathrm{a}, \mathrm{b}, *}$, Abe C. Lin ${ }^{\mathrm{c}}$ \\ ${ }^{a}$ Institute of Information Management, National Chiao-Tung University, 1001 Ta Hsueh Road, Hsinchu 300, Taiwan, ROC \\ ${ }^{\mathrm{b}}$ Internet Security Solutions International Co., Taiwan, ROC \\ ${ }^{\mathrm{c}}$ DCGS for Communications, Electronics and Information(J-6), Ministry of National Defense, Taiwan, ROC \\ Received 7 October 2002; received in revised form 16 January 2003; accepted 20 January 2003
}

\begin{abstract}
Current reliable strategies for information security are all chosen using incomplete information. With standards, problems resulting from incomplete information can be reduced, since with standards, we can decrease the choices and simplify the process for reliable supply and demand decision making. This paper is to study the certification of information security management systems based on specifications promulgated by the Bureau of Standards, Metrology and Inspection (BSMI), Ministry of Economic Affairs in accordance with international standards and their related organizations. And we suggest a certification requirement concept for five different levels of "Information and Communication Security Protection System" in our country, the Republic of China, Taiwan.
\end{abstract}

(C) 2003 Elsevier Science B.V. All rights reserved.

Keywords: Certification; Conformity Assessment Procedure; Information security management system; Standard; Trust

\section{Foreword}

The Executive Yuan of Republic of China (R.O.C.) is the highest administration unit in the country. The Chief of the Executive Yuan is like a premier in France. In May 2001, the president of R.O.C. ordered a study on "National Information and Communication Infrastructure Security Mechanism Plan.” In August, the president commanded that the National Security Council should make a proposal on "The Establish-

* Corresponding author. Tel.: +886-03-5712301; fax: +886-035723792 .

E-mail addresses: u8834811@cc.nctu.edu.tw, kjf@iss.com.tw (K.-J. Farn). ment of the National Plan for Protecting and Assuring the Critical Information and Communication Infrastructure," and submitted to the Executive Yuan for further tasks in order that in information and communication network resources can be fully used in an obstacle-free and secure environment by year 2008 . On February 5, 2001, the Executive Yuan of R.O.C sent out the "Plan for establishing the construction of basic information and communications security mechanisms in Taiwan" to each of its subordinate authorities, requesting active cooperation [1], thus officially turning a new leaf in the development of information security in Taiwan.

In recent years, several countries (e.g., the USA, the UK, China, and others) have invested great efforts in the construction of basic information security [2- 
4], and have added to the impact on Taiwanese society by the nationwide power outage on July 29, 1999 and the great earthquake on September 21, 1999. Hence, the competent authorities in the spring of 1999 began to realize the importance of security of basic communication and information construction, and as a result, they designed "Security mechanisms in Taiwan's basic communication and information construction." Due to the fact that Taiwan's current communication and information security measures are restricted by their limited nature and lack of overall protection, detection and restorative abilities, the National Information Infrastructure Work Group, in an attempt to efficiently meet the President's instructions, reviewed the related plans, and after careful studies, called the first "National Information and Communication Security Meeting" on January 31, 2001, trying to complete the "Plan for Establishing the Construction of Basic Information and Communications Security Mechanisms in Taiwan" in 4 years [5].

Before the aforementioned plan was officially accepted by the Executive Yuan, the number of people mobilized, the aspects involved and the depth of interactions with the society were unprecedented in the field of information security in Taiwan. And this may have far-reaching effects on the direction which the information security technologies will take in the future. According to the plan, the prime minister and the vice prime minister shall be the convener and the deputy convener, respectively, of the "National Information and Communication Security Meeting," and the convener of the "National Information and Communication Initiative" (NICI) shall be its executive director. The meeting shall set up seven work groups: an integrated operations work group, a danger report work group, a technical support center, an internet crime work group, an information gathering work group, an audit service work group and a standard specification work group responsible for initiating different aspects of the construction of basic national communications and information security. Among these work groups, the Ministry of Economic Affairs takes the main responsibility over the standard specification work group, with the assistance of the Executive Yuan's Research, Development and Evaluation Commission, the Ministry of National Defense, the Ministry of Transportation and Communication and the Ministry of
Finance. The main responsibilities are described in the following:

1. Setting standards for information and communication security technologies.

2. Setting standards for various institutions for handling information and communication security matters.

3. Planning the installation of monitoring technology for information and communication security.

4. Planning and installing the methods of certification of information and communication security.

5. Installing the procedure of the information and communication security.

To achieve the targets of the aforementioned plan, the BSMI has followed the criteria in Annex 1-3 to the Agreement of Technical Barriers to Trade in the Uruguay round of multilateral trade negotiations:

1. Formulating in the standards for Evaluation criteria for IT security (ISO/IEC 15408), Code of practice for information security management (ISO/IEC 17799), and Software Process Assessment (ISO/ IEC TR 15504).

2. Developing protection profiles of different products in the ISO/IEC 15408 series of standards (e.g., access control, cryptography, issue and management of Public Key Certificates) and the installation of their common monitoring techniques.

Table 1

Ten CISSP information systems security test domains are covered in the examination pertaining to the common body of knowledge [8]

\begin{tabular}{ll}
\hline Item & Knowledge domain \\
\hline 1 & Security management practices \\
2 & Access control systems \\
3 & Telecommunications and \\
network security & Cryptography \\
4 & Security architecture \\
5 & and models \\
& Operations security \\
6 & Applications and systems \\
7 & development \\
8 & Business continuity planning \\
& and disaster \\
& recovery planning \\
9 & Law, investigations, and ethics \\
10 & Physical security \\
\hline
\end{tabular}


Table 2

Brief history of information security management accreditation

\begin{tabular}{lll}
\hline Item & Year & Event \\
\hline 1 & 1990 & $\begin{array}{l}\text { The organization for information, } \\
\text { computer and communications policies } \\
\\
\end{array}$ \\
& under the Organization for Economic \\
& (OECD) starts drafting "Guidelines \\
& for the security of information systems."
\end{tabular}

1992 OECD officially passed the "Guidelines for the security of information systems on November 11, 1992.

1993 The British Department of Trade and Industry promulgated "A Code of Practice for Information Security Management."

1995 The UK specified the first part of the British Standard "A Code of Practice for Information Security Management" (BS 7799), and submitted it to the International Organization for Standardization (ISO) to become ISO DIS 14980.

1996 The review of the submission of the first part of BS 7799 to ISO was completed on February 24, 1996, and the result was that it was not qualified as an ISO standard.

1997 (a) On March 27, 1993, OECD announced "Guidelines for Cryptography Policy."

(b) The UK officially began to implement a pioneering plan for information security management accreditation.

(a) The UK announced part two of BS 7799 "Specification for information security management systems" as well as the basis for information security management accreditation.

(b) In October 1995 the European Union announced the "Data Protection Directive", to take effect on October 10, 1998, demanding the protection of personal data through an Adequacy Standard. was submitted to ISO for review.

The first part of the amended version of the BS 7799 passed the ISO review process on December 1, 2000, to become the international standard ISO/IEC 17799.

Part 2 did not pass the review process and will be amended according to the principles of Corporate Governance.

Table 2 (continued)

\begin{tabular}{|c|c|c|}
\hline Item & Year & Event \\
\hline 10 & 2001 & $\begin{array}{l}\text { (a) On September } 11 \text { and 12, 2001, OECD } \\
\text { in Tokyo asked the establishment of } \\
\text { information security standards for each } \\
\text { specific industry, in addition to the original } \\
\text { ISO/IEC } 17799 \text { basic standards. A task force } \\
\text { was formed to work out the information } \\
\text { security guideline. } \\
\text { (b) The UK announced BS7799-2: } 2002 \text { Draft } \\
\text { in November 2001, publicly soliciting } \\
\text { opinions, asking user organizations to submit } \\
\text { their opinions prior to March } 31,2002 \\
\text { for integration. The amended version of } \\
\text { BS7799-2 is set to be announced in June, } 2002 \text {. }\end{array}$ \\
\hline 11 & 2002 & $\begin{array}{l}\text { (a) On July } 25,2002 \text {, OECD published } \\
\text { "OECD Guidelines for the Security } \\
\text { of Information Systems and Networks-Towards } \\
\text { a Culture of Security." Replacing the old version } \\
\text { of November 26th, 1992. } \\
\text { (b) On September 5, 2002, BS 7799-2:2002 } \\
\text { version was also revised according to the } \\
\text { aforementioned guide. }\end{array}$ \\
\hline 12 & 2003 & $\begin{array}{l}\text { Information security management } \\
\text { certification is likely to become official } \\
\text { ISO standard } 17799 \text {. }\end{array}$ \\
\hline
\end{tabular}

Apart from the Australia, Brazil, Czech Republic, Canada, Denmark, Germany, Iceland, India, Ireland, Japan, Korea, Malaysia, the Netherlands, New Zealand, Norway, Poland, Singapore, South Africa, Sweden, Switzerland, Taiwan, UAE, the UK have currently agreed to adopt BS 7799 .

3. Making BS7799-2 (Information Security Management Part 2: Specification for Information Security Management Systems) a national standard, and installing a certification system for Taiwan's communication and information security management systems.

4. Installing procedures for communication and information security management systems accreditation and product certification and accreditation as well as laboratory accreditation in compliance with the requirements in ISO/IEC Guide 62, ISO/ IEC Guide 65 and ISO/IEC 17025.

The BSMI is in the process of promoting all the related tasks. This study briefly analyses the differences and similarities among certification of information security management systems, quality management systems and environmental management systems in Sections 2 and 3 propose a concept for fundamental certification standards according to various the risk 
classification in Taiwanese certification preparatory work. Section 4 describes the conclusion.

\section{The brief introduction of related information security management specifications}

The work to establish international approval procedures for information security management accreditation in the digital society can be traced back to November 1988. How should the Common Body of Knowledge (CBK) of the specialized personnel working with information security be accredited? An organization specialized in the accreditation of information security personnel, the International Information System Security Certification Consortium (ISC) $^{2}$ was established in Salisbury, England. To be approved by the $(\mathrm{ISC})^{2}$, one requires tests of 10 major $\mathrm{CBK}$ categories as in Table 1 (taking normally $6 \mathrm{~h}$ to answer 250 multiple-choice questions). Correct answers to $70 \%$ of the questions in combination with a minimum of 3 years working experience with information security related matters are needed to qualify as a Certified Information Systems Security Professional (CISSP). CISSP certification is not issued on a permanent basis, but the test must be taken once every 3 years, and only after passing the test will the person get a renewed certificate. The Canadian Information Processing Society (CIPS), the Computer Security Institute (CSI), and the Information Systems Security Association (ISSA) all recognize CISSP certification. Apart from (ISC) ${ }^{2}$, SANS and other organizations also have their series of accreditation tests for specialized information security techniques (e.g., UNIX Security, Intrusion Detection Systems). Apart from the certification of specialized information security personnel, the work to set the international standards for the specifications for the management of information systems security is in progress [6,7]. Table 2 gives a brief history of its development, and Table 3 gives an outline of its contents as submitted to ISO after amendments.

The ideas behind and the structure of the specifications for information security management certification are the same as for ISO 14001, as shown in Fig. 1. Systematized security concepts such as main requirements, goal management, risk prevention, law obedience, and continuous improvement are implemented according to a Plan-Do-Check-Action ( $\mathrm{P}-$
Table 3

The outline of amendments to BS7799 contents [6]

\begin{tabular}{|c|c|c|}
\hline Item & Control element & Amendment contents \\
\hline 1 & Security policy & $\begin{array}{l}\text { Enhance review and evaluation } \\
\text { session }\end{array}$ \\
\hline 2 & $\begin{array}{l}\text { Organizational } \\
\text { security }\end{array}$ & $\begin{array}{l}\text { (a) Enhance security of third-party } \\
\text { access session } \\
\text { (b) Increase outsourcing session }\end{array}$ \\
\hline 3 & $\begin{array}{l}\text { Asset classification } \\
\text { and control }\end{array}$ & $\begin{array}{l}\text { Enhance information labeling } \\
\text { and handling session }\end{array}$ \\
\hline 4 & Personnel Security & $\begin{array}{l}\text { Enhance learning form incidents } \\
\text { session }\end{array}$ \\
\hline 5 & $\begin{array}{l}\text { Physical and } \\
\text { environment security }\end{array}$ & $\begin{array}{l}\text { (a) Emphasizing office and } \\
\text { personnel security issues } \\
\text { (b) Reducing the number of special } \\
\text { requirements in a computer } \\
\text { center }\end{array}$ \\
\hline 6 & $\begin{array}{l}\text { Computer and } \\
\text { network management }\end{array}$ & $\begin{array}{l}\text { (a) Add details to the security of } \\
\text { open system } \\
\text { (b) Add publicly available systems } \\
\text { session } \\
\text { (c) Giving a new name } \\
\text { "Communications and } \\
\text { Operations Management" }\end{array}$ \\
\hline 7 & Access control & $\begin{array}{l}\text { (a) Enhance monitoring system } \\
\text { controls } \\
\text { (b) Add mobile computing and } \\
\text { tele-working }\end{array}$ \\
\hline 8 & $\begin{array}{l}\text { System development } \\
\text { and maintenance }\end{array}$ & $\begin{array}{l}\text { (a) Add cryptographic controls } \\
\text { session } \\
\text { (b) Add security in development } \\
\text { and support processes session }\end{array}$ \\
\hline 9 & $\begin{array}{l}\text { Business continuity } \\
\text { management }\end{array}$ & $\begin{array}{l}\text { Add details to impact analysis } \\
\text { and writing continuity plans }\end{array}$ \\
\hline 10 & Compliance & $\begin{array}{l}\text { (a) Enhancing compliance with } \\
\text { legal requirements } \\
\text { (b) Add regulation of cryptographic } \\
\text { controls and collection } \\
\text { of evidence sessions }\end{array}$ \\
\hline
\end{tabular}

D-C-A) cycle as shown in Fig. 2. Since risk appraisal includes all organizations and all departments, areas, staff and activities, the rationality and conformity of the appraisal is still a topic for research [9]. Compared to ISO 14001, it is more difficult. Fig. 3 is a graphic explanation of the information security management risk appraisal process. The risk management procedure in this figure-risk analysis aimed at risk extent definition and risk recognition and estimation, risk evaluation to decide project risk tolerability policies and responses and risk minimization and control when setting project policies - are based on implementation and audit. Fig. 4 is a schematic explanation of the 


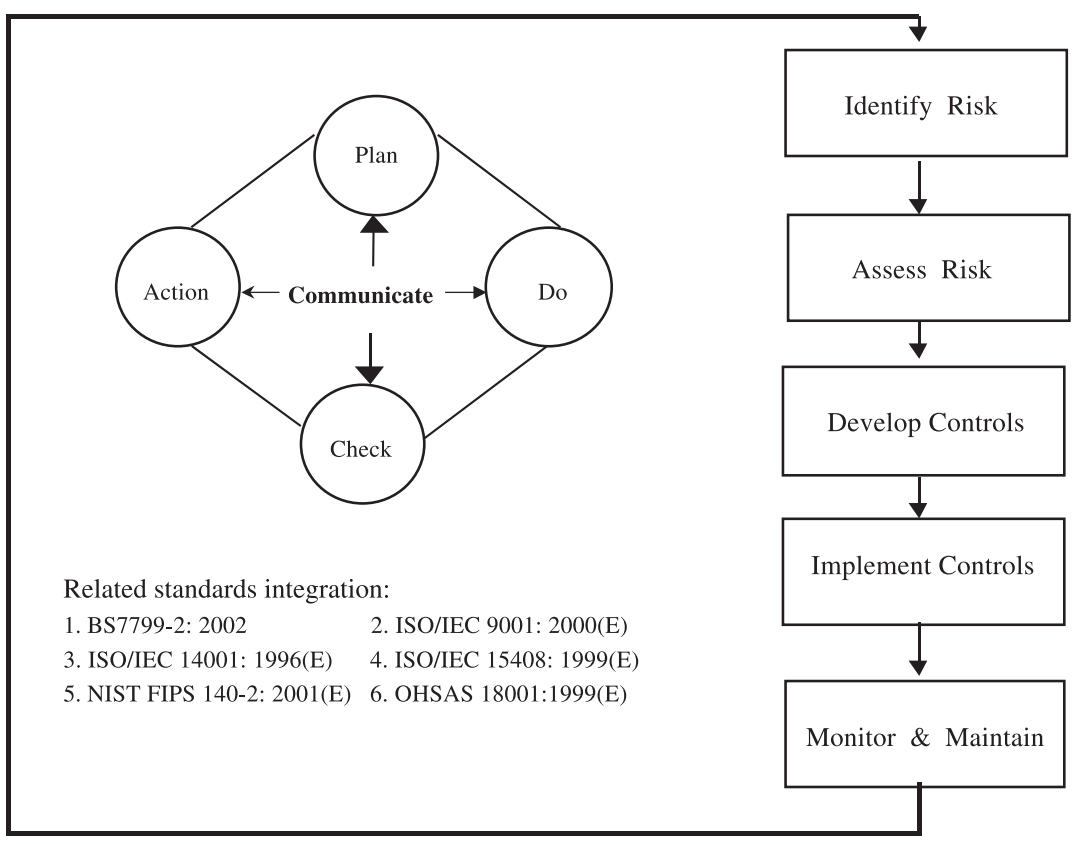

Fig. 1. Systematized security concepts.

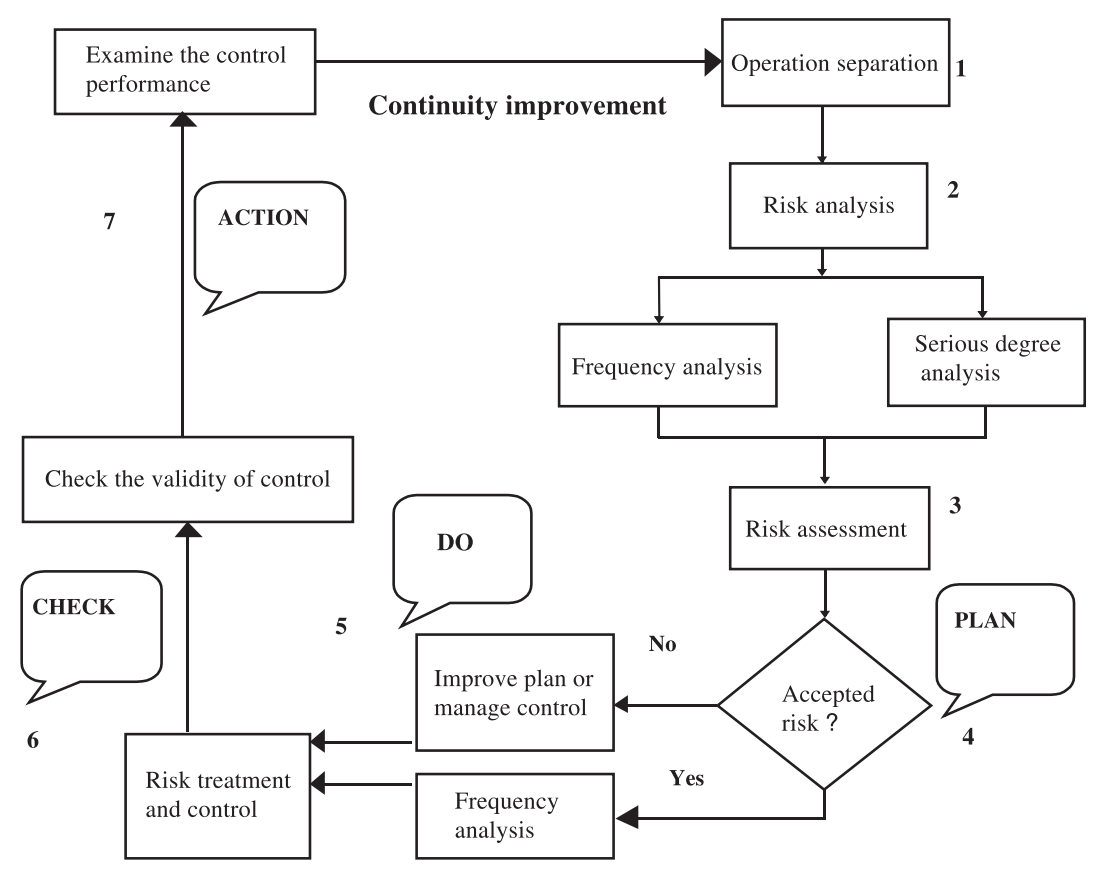

Fig. 2. The risk management model. 


Will any of the following threats
occur as a result of any of the
vulnerabilities listed on the
right?

- Unauthorized changes to, leaking or corruption of information

- Changes to, or corruption of information due to carelessness

- Non-delivery or improper delivery of information

- Denial of service or retrogression

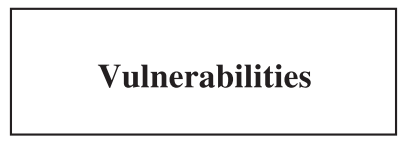

- Personnel

- Equipment and facilities

- Applications

- Communications

- Environment software and operating system

\section{Any production risk?}

- Loss of funds

- Loss of production capacity

- Embarrassment

Fig. 3. Risk analysis and risk assessment flow chart and explanation.

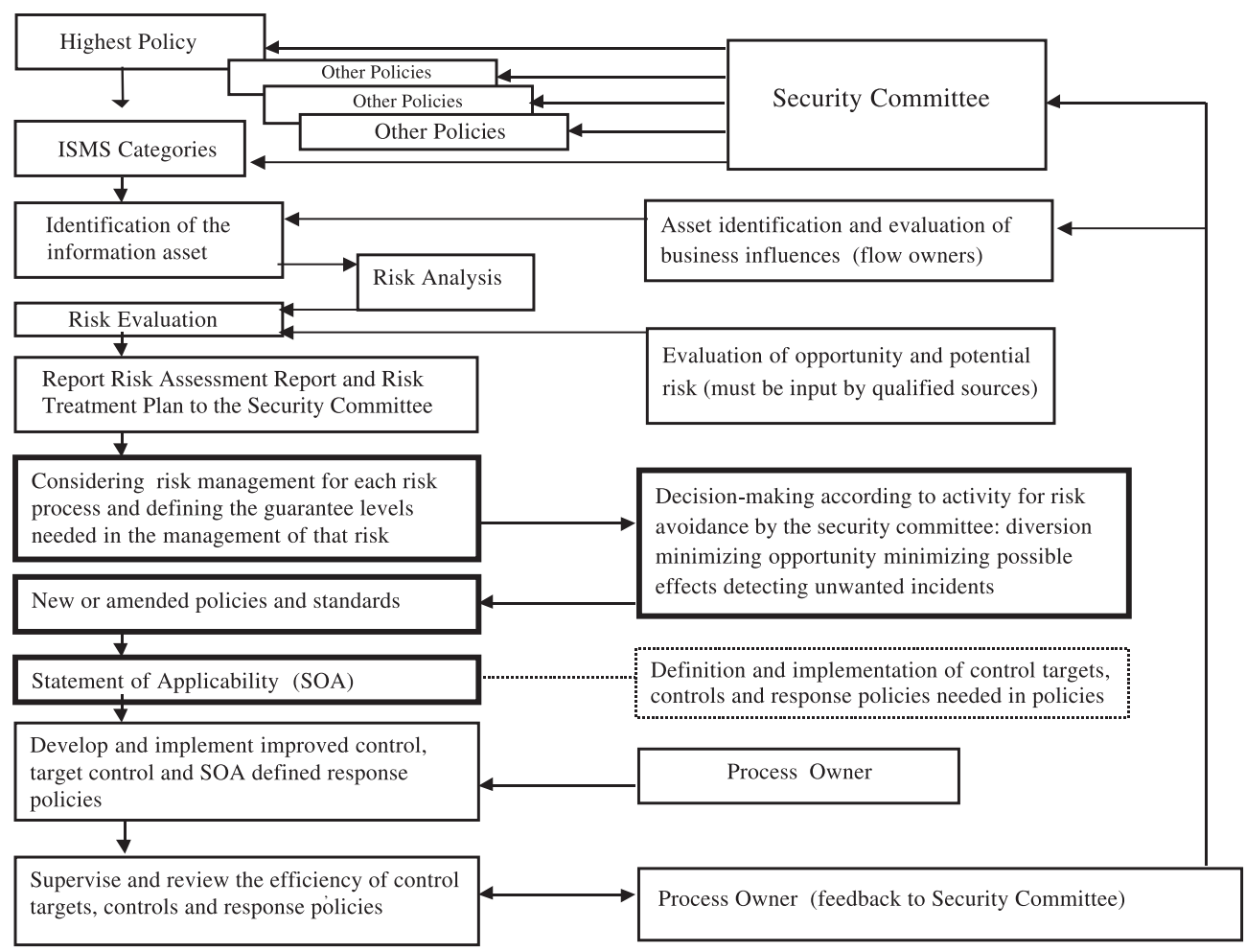

Fig. 4. Schematic explanation of communication and information security management risk appraisal. This diagram is cited and revised from Bsi BS7799 "Lead Auditor Course." 
Table 4

Information security characteristics

1. Confidentiality (C): Guarantees that the data only can be accessed by authorized personnel.

2. Integrity (I): Safeguarding of the accuracy and completeness of data and data processing methods.

3. Availability (A): Guarantees that data can be accessed through authorized personnel and used when needed.

risk management process $[10,11]$. Under normal circumstances, the risk created by a security incident is the monetary and production loss brought to each piece of information and assets by all threats through all weak points, and the totality of all kinds of risk to the organizational embarrassment. We use ISO/IEC TR 13335 methodology [12] to establish the risk management classification.

The four threats in Fig. 3 are in BS7799 abbreviated to threats $\mathrm{C}, \mathrm{I}$ and $\mathrm{A}$, as shown in Table 4, and the British Standards Institution (BSI) further integrates the compliance requirements described in the following designated L. as described in detail in Table 5. The use of the C, I, A and L threat categories will allow a more efficient choice of control targets and response policies for the Information Security Management System (ISMS).

Threat: information security related to any operational function, process or activity can be threatened in many ways. The banking industry has already defined four specific threats, which, if they occur, will weaken trust or completeness of operational functions, products or services or disturb operational sustainability.

\section{Table 5}

BS7799 integrates the compliance requirements $[6,7]$

(1) Compliance with legal requirements (ISO/IEC 17799: 2000(E), 12.1):

Objective: To avoid breaches of any criminal and civil law, statutory, regulatory or contractual obligations and of any security requirements.

(2) Reviews of security policy and technical compliance (ISO/IEC 17799: 2000(E), 12.2):

Objective: To ensure compliance of systems with organizational security policies and standards.

(3) System audit considerations (ISO/IEC 17799: 2000(E), 12.3):

Objective: To maximize the effectiveness of and to minimize interference to/from the system audit process.
The following table provides explanations for each of these four threats:

Threat
$\begin{aligned} & \text { Unauthorized changes to, } \\ & \text { leaking or corruption } \\ & \text { of information }\end{aligned}$

Changes to, or corruption of information due to carelessness

Non-delivery or improper delivery of information

Denial of service or retrogression

Explanation

This threat is made up of intentional or non-intentional release of information and intentional additions, changes or corruptions to information by the staff accessing or not accessing information processes in its normal dispensation of duties. This threat is made up of loss, addition, change or corruption of information due to carelessness, oversight or unintentional action. The possibility of this threat occurring arises out of human action or non-action, hardware, software or communication failure and natural disasters.

This threat is made up of information being unintentionally deleted or improperly delivered due to paper or digital formats. This includes hardware, software and communication failure and natural disasters.

This threat is made up of insufficient usability as a result of unplanned short-term or long-term retrogression occurring in the overall workflow or in part of the workflow.

Vulnerability: "vulnerability" refers to the ways by which a threat occurs.

The following table explains these vulnerabilities:

\begin{tabular}{ll}
\hline Vulnerability & Explanation \\
\hline Personnel & This vulnerability is attributed \\
& to the staff, manufacturers and \\
& hired personnel. When not \\
understanding or obeying the & department operational \\
procedure and control. & This vulnerability is caused by \\
the practical security of the work & area and equipment, and the \\
Equipment and & access to work area \\
facilities & and equipment. \\
\hline
\end{tabular}




\begin{tabular}{ll}
\hline Vulnerability & Explanation \\
\hline Applications & $\begin{array}{l}\text { This vulnerability is caused by } \\
\text { a company's procedures for } \\
\text { the processing of information. } \\
\text { Application involves the handling } \\
\text { of input and output. } \\
\text { This vulnerability occurs during } \\
\text { the electronic transfer of } \\
\text { information between two stations. } \\
\text { Communications } \\
\text { This vulnerability occurs in the } \\
\text { operating system and sub-systems } \\
\text { anvironment } \\
\text { software } \\
\text { and operating } \\
\text { system }\end{array}$ \\
$\begin{array}{l}\text { application software was } \\
\text { developed and is used. }\end{array}$ \\
\hline
\end{tabular}

Risk categories: there are three main risks that must be considered during risk appraisal.

The following table explains these risk categories:

\begin{tabular}{ll}
\hline Risk categories & Explanation \\
\hline Loss of funds & Loss of funds is defined as the \\
& loss of valuable objects or \\
& increased costs or expenses. \\
& The category business function \\
& risk will increase with the \\
& increased risk of fund losses \\
& or potential value \\
& Example \\
& Valuable objects \\
& - money \\
& - bonds \\
& - capital transfers \\
& Increased costs: \\
& - bond issue \\
& - theft \\
& - negative legal decision, etc. \\
& When the staff is unable to \\
& continue carrying out its duties \\
& or when duties must be \\
& repeated, loss of production \\
capacity will occur. When \\
business functions can no \\
longer be used, or when results \\
capacity
\end{tabular}

\section{Information security management system certification and accreditation mechanisms}

Owing to the speed with which quality and environmental management certification has developed in Taiwan, quality or certification is not standardized. This could easily have a negative impact on trades, and the Ministry of Economic Affairs on March 5, 1997, set and issued BCIQ order 86350708 "Implementation Rules for the Chinese Quality Management and Environmental Management Accreditation System," and on March 26 of the same year, it set and issued BCIQ order 86260244 "Points for the Establishment of the Chinese National Accreditation Board." On July 30, 1998, the Chinese National Accreditation Board (CNAB) began accepting applications for accreditation from relevant certification organizations and organizations training inspection personnel. Based on the definition in the Article 4 in the above-mentioned implementation rules:

1. Accreditation: The authority in charge issues an official written recognition that the certification or training organization is capable of implementing the regulated work processes or activities.

2. Certification: The certification organization issues a written guarantee that the inspectors, products, procedures or services comply with the procedures or activities specified in the regulations.

In response to the needs for certification of professional safety and health, fire security equipment and information security management systems, the Ministry of Economic Affairs on March 3, 2001, set and issued MOE (90) Accreditation 0900460122 "Implementation Regulation for Chinese National Accreditation Scheme." Apart from the original quality and environmental management, regular certification organizations (e.g., organizations for the certification of information security management systems) and the accreditation of product certification and inspection organizations are all the responsibility of the CNAB. On March 2, 2001, MOE (90) Accreditation document no. 09003504120 was issued, announcing the amendment of the "Points for the Establishment of the Chinese National Accreditation Board." In other words, as Fig. 5 shows, the agreement on technical trade barriers in the General Agreement on Tariff and 


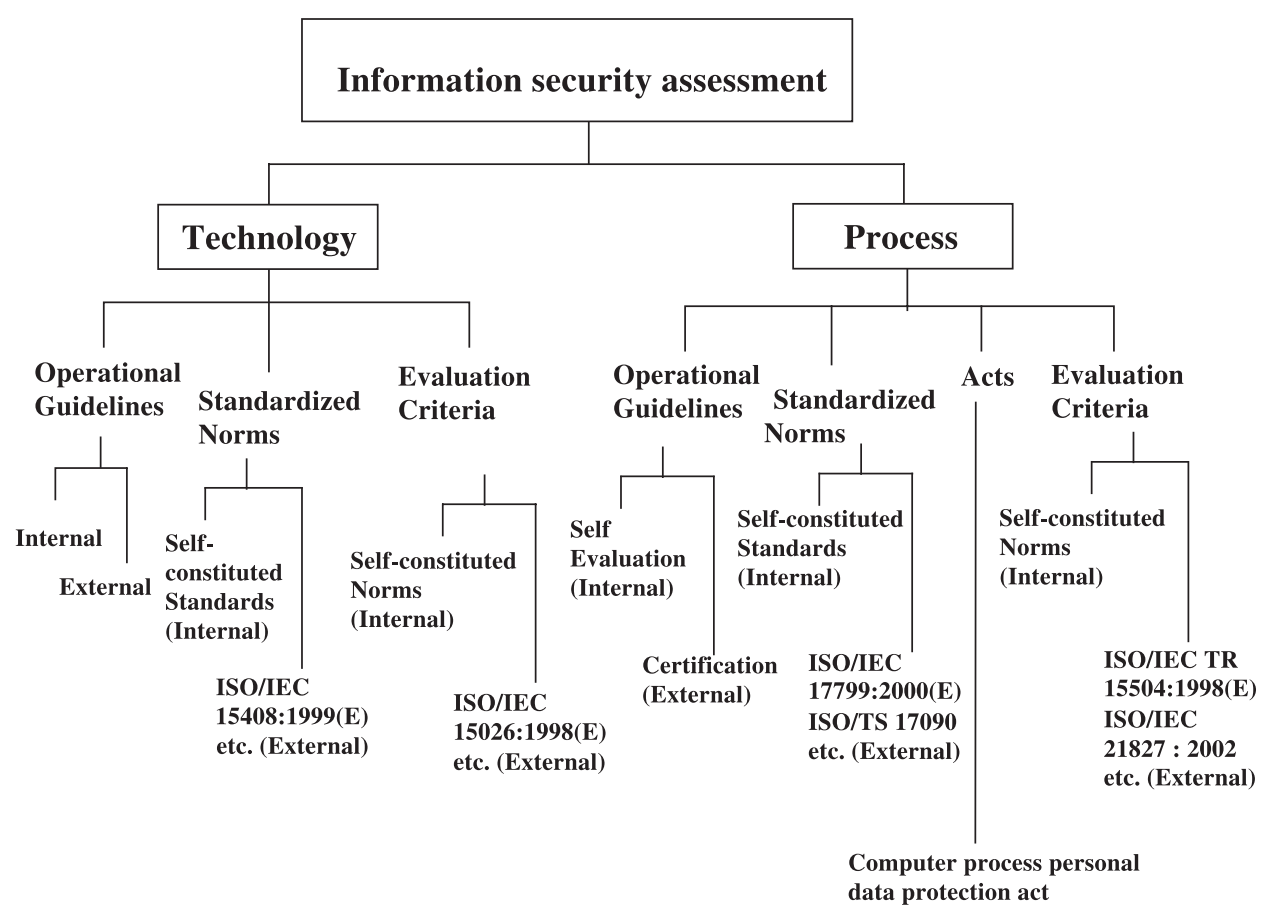

Fig. 5. The information security assessment explanation.

Trade (GATT) demands that each country, considering safety, health, environment and consumer protection factors, set technical laws or standards, and proves that related products conform to the Conformity Assessment Procedure (CAP) of these technical laws or standards and that they do not create any unnecessary barriers to international trades. Due to the lack of integrity and secure reliability of information, e-commerce and e-governments turning to digitization/Internet will never become active, and the virtual world will never go beyond cultural recreations and advertising framework. Services for the accreditation, certification

\begin{tabular}{|c|c|}
\hline General requirements : & Personnel requirements : \\
\hline 4.1 Security Policy & 4.4 Personnel Security \\
\hline 4.2 Organizational Security & 4.5 Physical and Environmental Security \\
\hline 4.3 Asset Classification and Control & System Development and Maintenance \\
\hline 4.9 Business Continuity Management & \\
\hline 4.10 Compliance & \\
\hline Physical and environmental & Information technology requirements : \\
\hline requirements : & 4.6 Communication and Operations \\
\hline 4.5 Physical and Environmental & Management \\
\hline Security & 4.7 Access Control \\
\hline & 4.8 System Development and Maintenance \\
\hline
\end{tabular}

Fig. 6. Requirement for ISMS accreditation and certification (BS7799-2). 
Table 6

U.S. Federal Deposit Insurance (FDIC) Division of Supervision (DOS) proposed a set of Electronic Banking Safety and Soundness Examination Procedures [13]

\begin{tabular}{ll}
\hline Level & $\begin{array}{l}\text { Electronic banking } \\
\text { functional explanation }\end{array}$ \\
\hline 1 & Information-only systems \\
2 & Electronic information transfer systems \\
3 & Fully transactional information systems \\
\hline
\end{tabular}

and inspection of information security mechanisms establishing an international digitized/Internet society has been directed by the CNAB since March 2, 2002. According to BSMI plans, ISMS accreditation and certification as shown in Fig. 6, is set to begin in March 2002.

There will be different security demands on information systems due to different working conditions, e.g., the Federal Deposit Insurance Corporation's (FDIC) Division of Supervision (DOS) proposed a set of Electronic Banking Safety and Soundness Examination Procedures (S\&S Exam.) aimed at differences in the characters of Internet banking services provided by financial institutions and the extent of risks faced, clearly dividing them into three different levels as shown in Table 6 [13]. Based on the management concepts shown in Table 7 [14], "Maturity of Information Risk Management" and "Risk Category

Table 7

Maturity of information risk management [14]

\begin{tabular}{ll}
\hline Maturity level & Description \\
\hline 0 & Non-existent: management processes are not applied at all
\end{tabular}

(a) No risk assessment of processes or business decisions. The organization does not consider the business impact associated with security vulnerabilities. Risk management has not been identified as relevant to IT solutions and services;

(b) The organization does not recognize the need for IT security. Responsibilities and accountabilities for security are not assigned. Measures supporting the management of IT security are not implemented. There is no IT security reporting or response process for IT security breaches. No recognizable security administration processes exist;

(c) No understanding of the risks, vulnerabilities and threats to IT operations or service continuity by management.

Initial/Ad-Hoc: processes are ad-hoc and disorganized

(a) The organization consider IT risks in an ad hoc manner, without following defined processes or policies. Informal project based risk assessment is used;

(b) The organization recognizes the need for IT security, but security awareness depends on the individual. IT security is reactive and not measured. IT security breaches invoke 'finger pointing' responses if detected, because responsibilities are unclear. Responses to IT security breaches are unpredictable;

(c) Responsibilities for continuous service are informal, with limited authority. Management is becoming aware of the risks related to and the need for continuous service.

Repeatable but intuitive: processes follow a regular pattern

(a) There is an emerging understanding that IT risks are important and need to be considered. Some approach to risk assessment exists, but the process is still immature and developing;

(b) Responsibilities and accountabilities for IT security are assigned to an IT security coordinator with no management authority. Security awareness is fragmented and limited. Security information is generated, but is not analyzed. Security tends to respond reactively to incidents and by adopting third-party offerings, without addressing the specific needs of the organization. Security policies are being developed, but inadequate skills and tools are still being used. IT security reporting is incomplete or misleading;

(c) Responsibility for continuous service is assigned. Fragmented approach to continuous service. Reporting on system availability is incomplete and does not take business impact into account.

Defined process: processes are documented and communicated

(a) An organization-wide risk management policy defines when and how to conduct risk assessments. Risk assessment follows a defined process that is documented and available to all staff;

(b) Security awareness exists and is promoted by management through formalized briefings. IT security procedures are defined and fit into a structure for security policies and procedures. Responsibilities for IT security are assigned, but not consistently enforced. An IT security plan exists, driving risk analysis and security solutions. IT security reporting is IT focused, rather than business focused. Ad hoc intrusion testing is performed;

(c) Management communicates consistently the need for continuous service. High-availability components and system redundancy are being applied piecemeal. An inventory of critical systems and components is rigorously maintained. 
Table 7 (continued)

\begin{tabular}{ll}
\hline Maturity level & Description \\
\hline 4 & Managed and measurable: processes are monitored and measured
\end{tabular}

(a) The assessment of risk is a standard procedure and exceptions would be noticed by IT management. It is likely that IT risk management is a defined management function with senior level responsibility. Senior management and IT management have determined the levels of risk that the organization will tolerate and have standard measures for risk/return ratios;

(b) Responsibilities for IT security are clearly assigned, managed and enforced. IT security risk and impact analysis is consistently performed. Security policies and practices are completed with specific security baselines. Security awareness briefings, user identification, authentication and authorization have become mandatory and standardized. Intrusion testing is standardized and leads to improvements. Cost/benefit analysis, is increasingly used. Security processes are coordinated with the overall organization security function and reporting is linked to business objectives;

(c) Responsibilities and standards for continuous service are enforced. System redundancy practices, including use of high-availability components, are being consistently deployed.

Optimized-best practices are followed and automated

(a) Risk assessment has developed to the stage where a structured, organization-wide process is enforced, followed regularly and well managed;

(b) IT security is a joint responsibility of business and IT management and integrated with corporate business objectives. Security requirements are clearly defined, optimized and included in a verified security plan. Functions are integrated with applications at the design stage and end users are increasingly accountable for managing security. IT security reporting provides early warning of changing and emerging risk, using automated active monitoring approaches for critical systems. Incidents are promptly addressed with formalized incident response procedures supported by automated tools. Periodic security assessments evaluate the effectiveness of implementation of the security plan. Information on new threats and vulnerabilities is systematically collected and analyzed, and adequate mitigating controls are promptly communicated and implemented. Intrusion testing, root cause analysis of security incidents and proactive identification of risk is the basis for continuous improvements. Security processes and technologies integrated organization wide;

(c) Continuous service plans and business continuity plans are integrated, aligned and routinely maintained. Buy-in for continuous service needs is secured from vendors and major suppliers.

Management" and referring to the regulations in other countries $[12,15]$, we categorize our ISMS certification into five categories as shown in Table 8, where category 3 and above connects to the certification of the international BS7799-2. Category 4 is designed to take different industry demands into consideration.

Table 8

The classification of certification in the ISMS

\begin{tabular}{ll}
\hline Categories & Requirements for certification \\
\hline 1 & (a) Compliance with legal requirements (BS 7799-2: 1999, 4.10.1). \\
& (b) Security policy (BS 7799-2: 1999, 4.1). \\
& (c) Asset classification and control (BS 7799-2: 1999, 4.3). \\
& (d) Protection against malicious software (BS 7799-2: 1999, 4.6.3). \\
& (e) Security in development and support processes (BS 7799-2: 1999, 4.8.5). \\
& (a) Requirements for Categories 1. \\
& (b) Compliance (BS 7799-2: 1999, 4.10). \\
& (c) Organizational security (BS 7799-2: 1999, 4.2). \\
& (d) User training (BS 7799-2: 1999, 4.4.2). \\
& (e) Responding to security incidents and malfunctions (BS 7799-2: 1999, 4.4.3). \\
& (f) Business continuity management (BS 7799-2: 1999, 4.9). \\
& Requirements for BS 7799-2:2002 Annex A. \\
& Requirements for BS 7799-2:2002 Annex A as well as requirements for different industries as shown in Fig. 8. \\
& Requirements for TQM (Total quality management, included BS 7799-2). \\
\hline
\end{tabular}




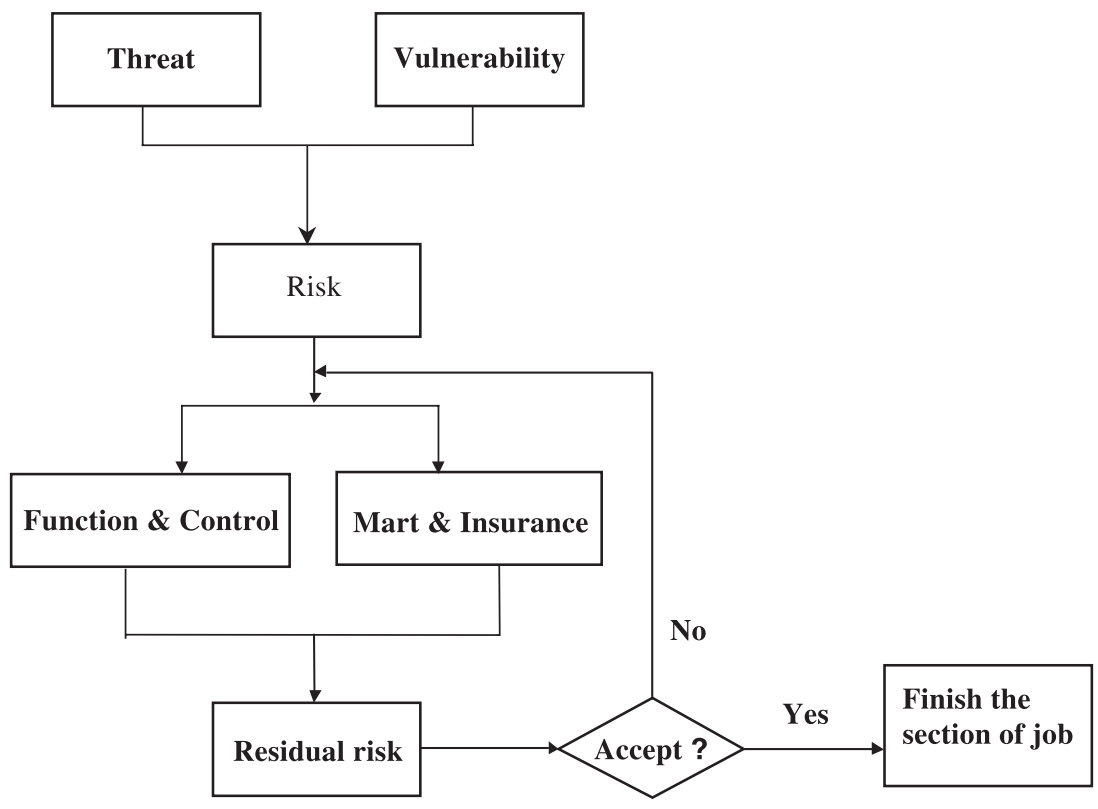

Fig. 7. Example of the application of risk analysis in the market and insurance mechanisms.

Category 5, apart from the requirements in BS7799-2, also has to consider the integrity of information security management systems and quality and environmental management systems. On the other hand, category 3 or above should apply the market and insurance mechanisms shown in Fig. 7 and Table 9 and reinforce the shortcomings of ISO/IEC 17799 shown in Fig. 8. Fig. 9 shows a reference flowchart

Table 9

The application of information security in the market and insurance mechanisms [16]

\begin{tabular}{|c|c|c|c|c|c|}
\hline Provider & Policy & Min. & Coverage premium & Notes limits & Source \\
\hline $\begin{array}{l}\text { Cigna property } \\
\text { and casualty }\end{array}$ & $\begin{array}{l}\text { Secure systems } \\
\text { insurance }\end{array}$ & $\$ 25,000$ & $\$ 25,000,000$ & $\begin{array}{l}\text { Requires security } \\
\text { assessment by } \\
\text { approved vendor }\end{array}$ & Mello (1998) \\
\hline $\begin{array}{l}\text { ICSA (International } \\
\text { Computer Security } \\
\text { Association) }\end{array}$ & TruSecure & $\$ 20,000$ & $\$ 250,000$ & $\begin{array}{l}\text { Requires ICSA } \\
\text { security review }\end{array}$ & $\begin{array}{l}\text { Attrino (1998), } \\
\text { Weise (1998) }\end{array}$ \\
\hline J\&H March & NetSecure & $\$ 5,000$ & $\$ 200,000,000$ & $\begin{array}{l}\text { Requires E-business } \\
\text { security assessment }\end{array}$ & netsecure.com (2000) \\
\hline Lloyds & $\begin{array}{l}\text { CIDSI (Computer } \\
\text { Information and } \\
\text { Data Security Insurance) }\end{array}$ & $\$ 10,000$ & $\$ 50,000,000$ & $\begin{array}{l}\text { Policy has Information } \\
\text { Risk Group (IRG) as } \\
\text { a required element }\end{array}$ & Koehn (1998) \\
\hline $\begin{array}{l}\text { Reliance } \\
\text { national/NRMS }\end{array}$ & InsureTRUST & & $\$ 10,000,000$ & $\begin{array}{l}\text { Requires NRMS } \\
\text { (Network Risk Mgt } \\
\text { Services of Atlanta) } \\
\text { review }\end{array}$ & Weise (1998) \\
\hline $\begin{array}{l}\text { Zurich Financial } \\
\text { Services Group }\end{array}$ & E-risk protection program & $\$ 4,000$ & $\$ 25,000,000$ & $\begin{array}{l}\text { Requires IBM } \\
\text { security certification }\end{array}$ & O’D. Moore (1999) \\
\hline
\end{tabular}

This figure covers the cost of the security review.

Ubizen has started providing security assessment services to policy holders on February 18, 2000. 


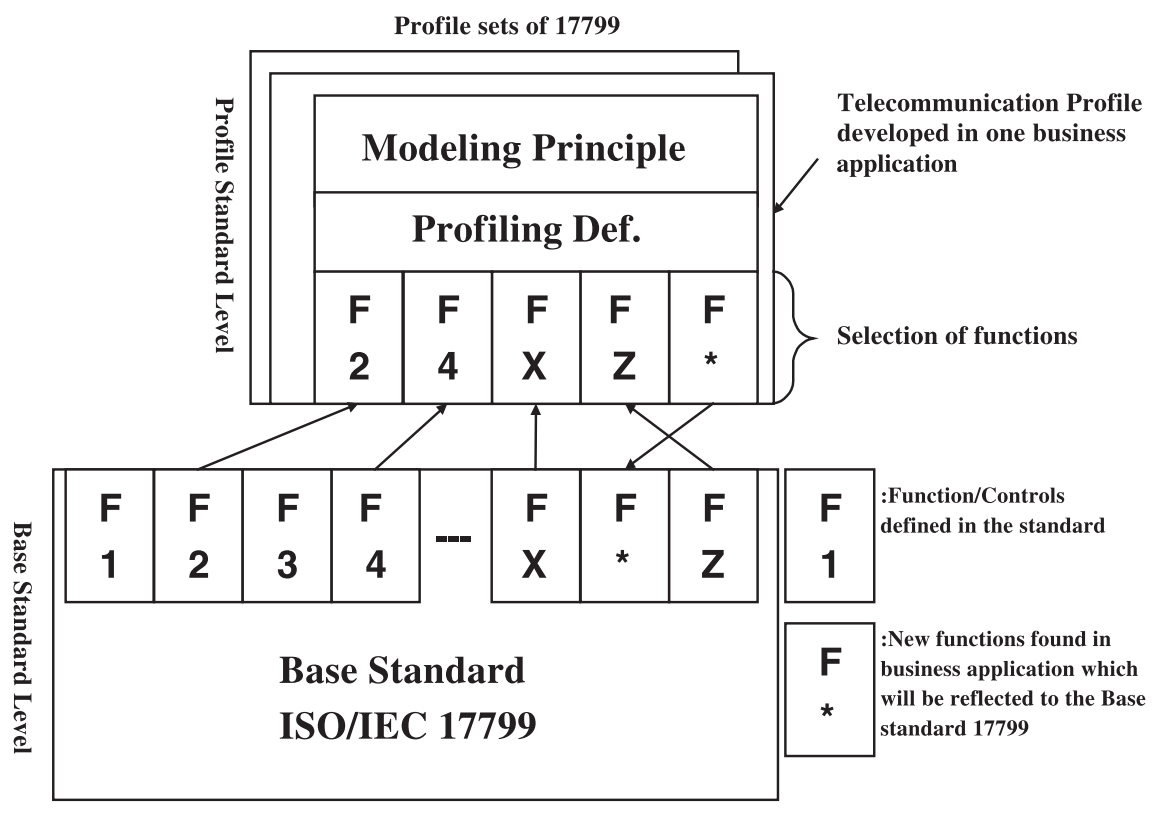

Fig. 8. The use of ISO/IEC 17799 in various industry information security management standards [17].

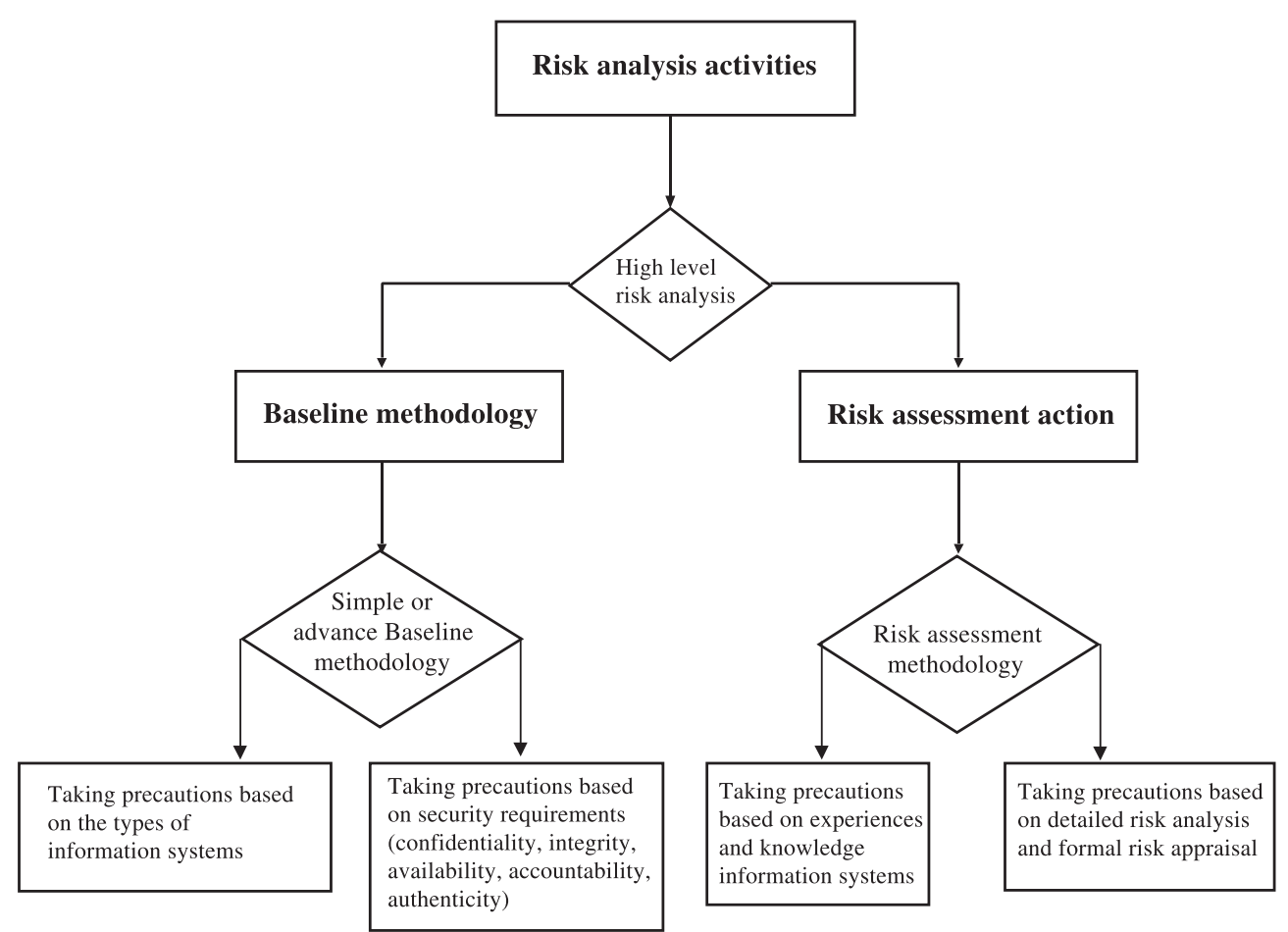

Fig. 9. Selection methods for ISMS protection [12]. 
of the decision procedure for the choice of information security management preventive measures [12].

\section{Conclusion}

The main goal of international standardization is to create a trade environment providing each of the following functions to promote the exchange of products.

1. Product quality and reliability and price concordance.

2. Guaranteeing the user's security and promoting the recycling of resources.

3. Goods, technology and service interoperability and mutual sequential continuity.

4. Simplification to reduce molding for a greater production capacity to reduce cost.

5. Simplification in order to diminish the frequency of modeling in the hope of expanding production scope and lower cost.

6. Improving the convenience of repair and maintenance and distribution efficiency.

In 1906, the beginnings of electrical technology started and in October 4, 1946, an international meeting was held in London, England, to promote international unification and adjustment of industrial standards officially and to establish the International Organization for Standardization (ISO). ISO began operating on February 23, 1947. October 14 is therefore also known as World Standards Day [18].

The so-called standards are unified regulations and simplified necessary timely conditions that provide a way of measuring objects, functions, installations, states, actions, control procedures, user instructions, work procedures, responsibilities and duties, concepts of power, and so on, based on fair, just, and convenient opinions. These specifications are the technical specifications in these standards that are directly or indirectly related to the quality of products or services. Normally, specifications or standards often pose different demands because of different types of organizations Tables 7 and 8 offer schematic explanations. The standards for implementing $\mathrm{P}-\mathrm{D}-\mathrm{C}-\mathrm{A}$ cycle in ISMS, as shown in Table 10.

The certification standards are proposed in the third section of this paper regarding the ability of Taiwan's
Table 10

The international ISMS standards in risk management cycle

\begin{tabular}{lll}
\hline \multicolumn{2}{l}{ Risk management level } & Requirements for risk level \\
\hline Cycle & Categories & \\
\hline Plan & & ISO/IEC TR 13335 \\
Do & 1 & ISO/IEC 17799 \\
& 2 & ISO/IEC 17799 \\
& 3 & ISO/IEC 17799 \\
& 4 & ISO/IEC 17799 plus \\
& industry-related standards \\
& (e.g., Health informatics-Public \\
& & Key Infrastructure (PKI) must \\
& & comply with ISO/TS 17090, too) \\
& & The integration of ISO/IEC 17799, \\
& & industry-related standards, \\
& & ISO 9000, and ISO 14000 into ISMS \\
& & BS 7799-2:2002 \\
Check & & The standards listed in Fig. 5 \\
Action &
\end{tabular}

information security management systems (levels 15) to meet the international systems (levels 3-5) demands on functional standards for certification specifications for relevant information technology on different types of organizations still need to be further researched [19].

Global civilization experienced great changes in the 1990s. Quality, environmental, safety and health management gradually moved towards conformity and standardization, and related international standards also affected the economic development in many nations, as well as their organizational management and operations. The best evidence of this is the abidance by the ISO 9000 series of standards for quality management and the ISO 14000 series of standards for environmental management. International standards for information security management issued in the last month of the 20th Century have become a guide for the construction of a reliable information environment. If appropriately used, this will not only improve the security of information systems, but it will also help shape a culture of quality.

\section{Acknowledgements}

We would like to express our appreciation to the reviewers for their suggestions and comments. Their input have greatly upgraded our paper. 


\section{References}

[1] The Executive Yuan of Republic of China (R.O.C.), February 5, 2001 (90) MOE document no. 007431 (2001).

[2] The White House, National Plan for Information Systems Protection Version 1.0 (2000) 101-102.

[3] F.B. Schneider, Trust in Cyberspace, National Academic Press, New York, U.S.A., 1999.

[4] A. Rathmell, Protecting critical information infrastructures, Computers and Security 20 (2001) 43-52.

[5] National Information Infrastructure Group (NII), the Executive Yuan of R.O.C., The first meeting of the National information and communication security meeting (meeting data). National Information Infrastructure Group, Executive Yuan, (2001).

[6] ISO (International Organization for Standardization)/IEC (International Electro-technical Commission), Information Technology - Code of Practice for Information Security Management. ISO/IEC 17799. 2000 (E), ISO, (2000).

[7] BSI (British Standards Institution), Information Security Management-Part 2: Specification for Information Security Management Systems. BS7799-2:1999; Information Security Management Systems - Specification with guidance for use. BS7799-2:2002, BSi (2002), September, London.

[8] R.L. Krutz, R.D. Vines, The CISSP Prep Guide: Mastering the Ten Domains of Computer Security, Wiley, Washington, D.C., U.S.A., 2001.

[9] Bureau of Standards, Metrology and Inspection, MOE, collected papers from the APEC-SBS Seminar, September 22, 2001, Taipei City, Bureau of Standards, Metrology and Inspection, Ministry of Economic Affairs (2001).

[10] IEC, Dependability Management - Part 3: Application GuideSection 9: Risk Analysis of Technology Systems. IEC 300-39, 1995, IEC (1995).

[11] ISO, Banking, Securities and Other Financial Services-Information Security Guidelines. ISO TR 13569: 1997(E), ISO (1997).

[12] ISO, Information Technology - Guidelines for the Management of IT Security, Parts 1-5. ISO/IEC TR 13335 (All Parts), ISO (2001).

[13] U.S. Federal Deposit Insurance Corporation, Division of Supervision. Electronic Banking: Safety and Soundness Examination Procedures (1998).

[14] P. Williams, Information security governance, Information Security Technical Report 6 (3) (2001) 60-70.

[15] B. Solms, R. Solms, Incremental information security certification, Computers and Security 20 (4) (2001) 308-310.

[16] R.C. Reid, S.A. Floyd, Extending the risk analysis model to include market-insurance, Computers and Security 20 (4) (2001) 331-339.

[17] OECD Workshop, OECD Workshop Information Security in a Network World, 12-13, September 2001, Tokyo, Japan.

[18] C. Shu-The, A study into the internationalization of national standards. Bureau of Standards, Metrology and Inspection, Ministry of Economic Affairs, 1990.

[19] ISO, Health informatics - Public Key Infrastructure Part 1-3, ISO/TS 17090 (All Parts), ISO, 2002.

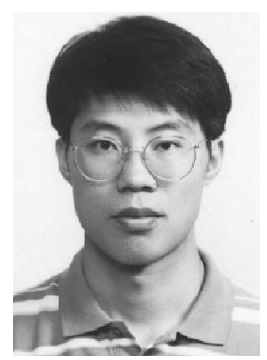

Andrew Ren-Wei Fung received his BBA and MS degrees in Information Management from the National Defense Management College, Taiwan, in 1987 and 1995, respectively. He is currently a $\mathrm{PhD}$ candidate at the Institute of Information Management, National Chiao Tung University (NCTU), Hsinchu, Taiwan. His research interests include Information Security and Parallel Computing.

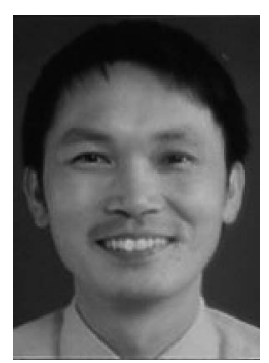

Kwo-Jean Farn is director of the R\&D Department at Taiwan Internet Security Solutions, Co. and a part-time associate professor at the National Chiao Tung University (NCTU) in Taiwan. He received his $\mathrm{PhD}$ degree in 1982. His extensive experience includes a 20 -year career in Information Technology and a 10-year career in Information Security. He served as chair of the Implementation Critical Information Infrastructure Protection Project at Computer and Communications Research Laboratories/Industrial Technology Research Institute (CCL/ITRI) in Taiwan from 1999 to September 2000. He has worked at ITRI for more than 18 years until the summer of 2001. He holds eight patents in the area of Information Security.

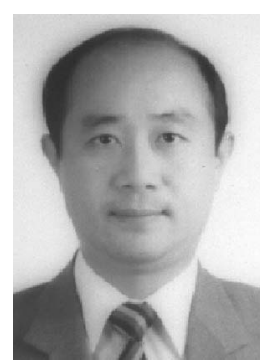

Lieutenant General Abe C. Lin was appointed as Deputy Chief of General Staff for Communications, Electronics and Information (J-6) of the MND on March 1, 2002. J-6 directs and oversees the policy of C4ISR, Electronic and Information Warfare, Communications, and Information security of the Republic of China on Taiwan. In the year 2000, the Government of Taiwan appointed Gen. Lin to the post of Deputy executive Secretary of the National Information and Communications Initiatives (NICI) of the Government of Taiwan. In an additional capacity, Gen. Lin has been facilitating the establishment of a national-level network security infrastructure. General Lin, who graduated from Taiwan Air Force Academy in 1970, earned his Master's Degree in Business Administration from the National Taiwan University of Science and Technology, and his Master's Degree in Electrical Engineering from the University of Illinois. He has also published numerous papers and dissertations to express his ideas. These papers have received strategic attention from the Government of Taiwan and the academia. 